This is an author produced version of a paper published in Clin Chim Acta. This paper has been peer-reviewed but does not include the final publisher proof-corrections or journal pagination.

Citation for the published paper:

Agardh, Daniel and Roth, Bodil and Lernmark, Ake and Stenberg, Pål "Calcium activation of tissue transglutaminase in radioligand binding and enzymelinked autoantibody immunoassays in childhood celiac disease"

Clin Chim Acta. 2005 Aug;358(1-2):95-103

http://dx.doi.org/10.1016/j.cccn.2005.02.027

Access to the published version may require journal subscription.

Published with permission from: Elsevier 
Revision submitted to Clinica Chimica Acta (2006-01-10)

\section{Calcium activation of tissue transglutaminase in radioligand binding and enzyme-linked autoantibody immunoassays in childhood celiac disease}

Short title: Tissue transglutaminase and calcium

Daniel Agardh ${ }^{1,2 *}$, Bodil Roth ${ }^{3,4 *}$, Åke Lernmark ${ }^{2,5}$, Pål Stenberg ${ }^{3}$

${ }^{1}$ Department of Pediatrics, University Hospital MAS, Lund University, Malmö, Sweden

${ }^{2}$ Department of Endocrinology, Wallenberg Laboratory, Lund University, Malmö, Sweden

${ }^{3}$ Hospital Pharmacy, University Hospital MAS, Malmö, Sweden

${ }^{4}$ Department of Medicine, University Hospital MAS, Malmö, Sweden

${ }^{5}$ RH Williams Laboratory, Department of Medicine, University of Washington, Seattle, WA, USA.

*Contributed equally to this article

Corresponding author: Daniel Agardh, MD, Department of Pediatrics, University Hospital MAS, S-205 02 Malmö, Sweden, Telephone: +46-40-33 23 90, Fax: +46-403370 42,

E-mail: daniel.agardh@home.se

Keywords: Calcium, celiac disease, ELISA, radioimmunoassays, tissue transglutaminase. 


\section{Abstract}

Background: Conflicting data have been published concerning the effect of calcium on binding of autoantibodies to tissue transglutaminase (tTG) in celiac disease (CD).

Methods IgA-tTG and IgG-tTG were measured with radioligand binding assays (RBA) using human recombinant (hr) ${ }^{35} \mathrm{~S}$-tTG produced in lysate of rabbit reticulocytes and with guinea pig (gp) tTG ELISA in 51 CD children (median 5.7 years) and 35 controls (median 2.2 years). Assays were performed with and without calcium.

Results: In hr-tTG RBA, IgA-tTG levels remained unchanged after calcium detecting 50/51 CD children and 1/35 controls $(\mathrm{p}<0.0001)$. IgG-tTG levels decreased with calcium ( $\mathrm{p}=0.002$ ) in CD children and detected 48/51 with and 49/51 without calcium as compared to $1 / 35$ controls $(\mathrm{p}<0.0001)$. In gp-tTG ELISA, levels increased with calcium $(\mathrm{p}<0.0001)$ making it possible to detect an additional three to a total of 50/51with IgA-tTG and 13 to 39/51 CD children with IgG-tTG compared to 4/35 and 8/35 controls (respectively, $\mathrm{p}<0.0001$ ). Rabbit reticulocytes displayed calcium dependent tTG activity.

Conclusions: Calcium increased binding of IgA-tTG and IgG-tTG in the ELISA test. The reverse effect observed in RBA may be explained by competitive binding between calcium activated native rabbit reticulocyte tTG and hr ${ }^{35}$ S-tTG. tTG autoantibody assays may need taking calcium into account for accurate diagnostic sensitivity and specificity for CD. 


\section{Introduction}

Transglutaminases are a widely distributed group of enzymes that catalyze posttranslational transamidation of proteins and peptides [1]. Human tissue transglutaminase (tTG) is a protein of 686 amino acids representing a molecular mass of $80 \mathrm{kDa}$ encoded by the TGM2 gene located on chromosome 20q11-12 [2]. tTG is one of several calcium dependent transglutaminases and is very fragile, especially in the presence of calcium or contaminating proteases [3]. In the absence of a primary amine, or at a lower $\mathrm{pH}$, tTG can catalyze the hydrolysis of specific peptide-bound glutamine residues to glutamic acid [4].

For the laboratory diagnosis of celiac disease (CD) determination of endomysial antibodies (EMA) has long been utilized [5]. It has further been shown that tTG is the main autoantigen of EMA [6]. This important finding launched a series of reports describing various ELISA for the determination of antibodies against tTG [7-12]. Similarly, methods based on radioimmunoassays have been published [13-17]. Both methods have shown high diagnostic sensitivity and specificity for $\mathrm{CD}$, although the expression of tTG antibodies may be reduced in infants making the diagnosis of CD during early childhood a laboratory challenge $[13,18]$.

It has been known for a long time that all transglutaminases are reversibly calcium dependent. The structural basis for this regulation has been elucidated [19]. Thus, the antibody binding capacity of tTG might also be affected by calcium. Indeed, we have previously shown that the presence of calcium during coating significantly increases the binding of antibodies from CD patients to guinea pig (gp) tTG on ELISA plates [3]. Similar findings have been reported by others [9, 20, 21], but not by all laboratories [22]. Unfortunately, the available information about the presence of calcium in the commercial kits is limited [12]. 
In radioligand binding assays (RBA) the antigen is kept in solution during the whole antibody binding process. Thus, the effects of calcium might differ from what is observed with the ELISA. For example, Nakachi et al. did not observe any significant effect of calcium in the immune precipitation assay [22].

The aim of the present study was to investigate whether calcium influenced the binding of IgA and IgG autoantibodies against hr-tTG analyzed with RBA compared with an optimized gp-tTG ELISA test in children with CD. 


\section{Materials and methods}

Serum samples were obtained from 86 children (49 females, 37 males, median 4.2 years (range 0.7-19.0)) who were consecutively investigated with intestinal biopsy at the Department of Pediatrics, University Hospital MAS in Malmö, during the years 20002003. In addition to the standard diagnostic procedures, all biopsy sections were coded and re-examined blinded by one pathologist according to a modification of Marsh criteria [23]. In cases where the opinion on biopsies diverged between the pathologists, CD was considered likely if the patient also had positive EMA titers. A total of 51 children (33 females, 18 males, median 5.7 years (range 0.7-19.0)) were considered to have active CD according to the revised ESPGHAN criteria [24], among them one child with IgA deficiency. The remaining 35 children (16 females, 19 males, median 2.2 years (range 0.7-14.3)) were included as disease controls, of whom ten were diagnosed with cow's milk protein or food allergy, nine were examined for failure-to-thrive or short stature, three had lipase deficiency and 13 children had transient gastrointestinal symptoms. The Ethics Committee of Medical Faculty, Lund University approved the intended use of all patient samples and the re-examination of coded biopsy sections.

\section{Activity Staining Procedure}

Erythrocytes from human EDTA blood $(4 \mathrm{~mL})$ were washed repeatedly at $4{ }^{\circ} \mathrm{C}$ with saline containing $2 \mathrm{mM}$ EDTA and centrifuged at 150, 175, 200 and $1000 * \mathrm{G}$, respectively. A $20 \mu \mathrm{l}$ solution of 2\% Triton X-100 (Sigma) in Tris-Cl (50mM, pH 7,4) containing 2 mM EDTA was added to the cell pellet. After sonication for 5 minutes the mixture was frozen at $-20{ }^{\circ} \mathrm{C}$, thawed after 2 hours and centrifuged at $4{ }^{\circ} \mathrm{C}$ for 10 minutes at $1000^{*} \mathrm{G}$. Aliquots of the supernatant were then applied to the agarose gel. Agarose gel electrophoresis was performed according to Laurell [25] at $\mathrm{pH} 8.6$ and in the presence of EDTA. Staining for TG activity was performed according to Stenberg 
and Stenflo [26]. The technique is based on the transglutaminase-catalyzed incorporation of a fluorescent amine (monodansylthiacadaverine hemifumarate (MDTC), Larodan Fine Chemicals, Malmö, Sweden) into casein. Briefly, after agarose gel electrophoresis the gel was covered with a piece of filter paper moistened with a freshly prepared solution $\left(0.1 \mathrm{~mL} / \mathrm{cm}^{2}\right)$ comprising MDTC $(0.7 \mathrm{mM})$, casein $(7 \mathrm{~g} / \mathrm{L})$, 1,4-dithiotreitol (Merck, Germany) (10 mM), thrombine (25 U/mL) (Parke Davis, USA) and calcium chloride $\left(\mathrm{CaCl}_{2}\right)(7 \mathrm{mM})$ in Tris-Cl $(50 \mathrm{mM} \mathrm{pH} 7.5)$ or EDTA $(2 \mathrm{mM})$ in Tris-Cl (50 mM pH 7.5). After incubation for approximately 1 hour at $37{ }^{\circ} \mathrm{C}$ filter paper was removed and the gel was treated with $10 \%$ aqueous trichloroacetic acid after which the excess of MDTC was removed by repeated washes with $10 \%$ aqueous acetic acid and finally with Tris-Cl until neutral. The gels were illuminated at $254 \mathrm{~nm}$ and photographed with a camera equipped with a UV filter and Polaroid film.

\section{Human recombinant (hr) tTG RBA}

Human tTG was synthesized by in vitro transcription and translation as described elsewhere [27]. One microgram of tTG cDNA (kindly provided by George Eisenbarth) subcloned into the pGEM-T Easy Vector (Promega, Madison, WI, USA) was labeled using the TNT SP6 coupled reticulocyte lysate system (Promega, Madison, WI, USA) in the presence of $20 \mu \mathrm{Ci}{ }^{35} \mathrm{~S}$-methionine (Amersham Pharmacia Biotech, Piscataway, NJ, USA). The in vitro transcription and translation was carried out in an EGTA containing buffer (personal information, Promega, Madison, WI, USA). Efficiency of incorporation (typically 15-20\%) of the radioactive label was measured by trichloroacetic acid precipitation of the translational product. Before tTG antigen was added to the micro-titer wells, it was freshly diluted in a solution containing of $100 \mu \mathrm{L}$ of $50 \mathrm{mM}$ Tris- $\mathrm{HCl}, 150 \mathrm{mM} \mathrm{NaCl}$, $\mathrm{pH} 7.4$ (TBS), with either $5 \mathrm{mM} \mathrm{CaCl}_{2}$ or $2 \mathrm{mM}$ EDTA. The RBA was run as described previously [28] with several modifications. 
When analyzing IgG antibodies, $300 \mathrm{cpm} / \mu \mathrm{l}$ of ${ }^{35} \mathrm{~S}$-tTG was diluted in wash buffer (20 $\mathrm{mM}$ TrisHCl, $\mathrm{pH}$ 7.4, $150 \mathrm{mM} \mathrm{NaCl,}$ 0.1\% BSA, 0.15\% Tween, either $5 \mathrm{mM} \mathrm{CaCl}_{2}$ or 2 mM EDTA) and $72 \mu \mathrm{L}$ of the antigen solution was added together with $3 \mu \mathrm{l}$ of human serum into a U-bottom 96-well micro-titer plate and incubated overnight at $4{ }^{\circ} \mathrm{C}$. Protein A sepharose (PAS) (Sigma, St.Louis, MO, USA) was used to separate the free from antibody bound ${ }^{35}$ S-tTG. A 96-well Multiscreen filtration plate (MABVNOB opaque; Millipore, Burlington, MA, USA) was pre-coated with $150 \mu \mathrm{L}$ per well of $0.5 \%$ bovine serum albumin (BSA) (Sigma, St.Louis, MO, USA) stored overnight at $4{ }^{\circ} \mathrm{C}$, washed twice with $200 \mu \mathrm{l} /$ well of wash buffer after which $50 \mu \mathrm{L} /$ well of $30 \%$ PAS and $50 \mu \mathrm{L}$ immunoprecipitated ${ }^{35} \mathrm{~S}$-tTG serum were added. The plate was then incubated on a plate shaker for 45 minutes at $4{ }^{\circ} \mathrm{C}$. IgA antibodies were analyzed similarly except that all patient sera samples were diluted 1/4 in wash buffer before adding $2.5 \mu \mathrm{L}$ of human serum and $60 \mu \mathrm{L}$ of ${ }^{35} \mathrm{~S}$-tTG solution to the 96 well microtiter plate. Goat anti-human IgA-agarose (Sigma, St.Louis, MO, USA) was used instead of PAS and $50 \mu \mathrm{l}$ of $10 \%$ IgA agarose solution containing $1 \%$ normal human serum and $50 \mu \mathrm{L}$ of immunoprecipitated ${ }^{35}$ S-tTG serum were added to each well. Finally, the plate was washed eight times with wash buffer containing either $5 \mathrm{mM} \mathrm{CaCl}_{2}$ or $2 \mathrm{mM}$ EDTA before drying, $50 \mu \mathrm{L} /$ well of Optiphase Super-mix scintillation cocktail (Wallac, Turku, Finland) was added and the reactivity was measured in a MicroBeta Counter (Wallac, Turku, Finland). Autoantibody levels were expressed as relative units (RU) in reference to positive and negative sera: $\mathrm{RU}=(\mathrm{cpm}$ of sample-mean $\mathrm{cpm}$ of two negative controls)/(cpm of positive control-mean cpm of two negative controls)*100. Using a cut-off level representing the $99.9^{\text {th }}$ percentile of healthy control subjects, sera yielding test results $\geq 3.5 \mathrm{RU}$ for IgA-tTG and $\geq 11.8 \mathrm{RU}$ for IgG-tTG, respectively, were considered as positive [29]. Both the intra- and inter-assay variations were $\leq 10 \%$. 


\section{Guinea pig (gp) liver tTG ELISA}

For the analysis of IgA-tTG and IgG-tTG, gp-tTG (Sigma lot 122K7435) was used as antigen. Microtiter plates (Covalink, Nunc, Rochester, NY, USA) were coated with $1 \mu \mathrm{g}$ gp-tTG/well, freshly prepared with $100 \mu \mathrm{l}$ of $50 \mathrm{mM}$ Tris-HCl, $150 \mathrm{mM} \mathrm{NaCl,} \mathrm{pH} 7.4$ (TBS) and with either $5 \mathrm{mM} \mathrm{CaCl}{ }_{2}$ or $2 \mathrm{mM}$ EDTA. After incubation overnight at $4^{\circ} \mathrm{C}$ the plates were washed three times with washing solution (TBS with $10 \mathrm{mM}$ EDTA and 0.1\% Tween 20) and blocked for 30 minutes at room temperature with blocking solution (TBS with 0.5\% Tween 20). Sera from patients with CD and healthy blood donors were diluted 400 times with blocking solution, and $100 \mu$ l diluted serum were added to each well in duplicate followed by incubation for 1 hour at room temperature. The washing procedure was repeated as above and $100 \mu \mathrm{L}$ of either peroxidaseconjugated anti-human IgG (DAKO, Denmark), 1:5000, or peroxidase-conjugated antihuman IgA (DAKO, Denmark), 1:1000, diluted in washing solution, were added to each well. After one hour of incubation at room temperature the washing procedure was repeated. The plates were developed according to standard procedure with $1 \mathrm{mg}$ OPD/ml, $0.1 \mathrm{M} \mathrm{Na-citrate}$ at pH 4.2 (DAKO, Denmark), and 0.06\% $\mathrm{H}_{2} \mathrm{O}_{2}$. After incubation at room temperature for 1 hour in darkness, the enzyme reaction was stopped by the addition of $100 \mu \mathrm{L} 0.5 \mathrm{M} \mathrm{H}_{2} \mathrm{SO}_{4} /$ well. Absorbance was estimated at $490 \mathrm{~nm}$ in a micro plate-reader (E max, Molecular Device, CA, USA). Intra-assay CV ( $n=8)$ was 3.0\% for IgA-tTG and 8.6\% for IgG-tTG while inter-assay CV was $6.1 \%$ for both IgAtTG and IgG-tTG. The cut-off levels of normal for the assay containing $\mathrm{CaCl}_{2}$ were estimated at 249 AU for IgA-tTG and 330 AU for IgG-TG, respectively. For the EDTA assay, the cut-off levels of normal were 299 AU for IgA-tTG and 387 AU for IgG-tTG. The cut-off levels represented the mean \pm SD of 59 normal blood donors ( 29 females, 30 males, mean age 42, (range 19-65)) (data not shown). 


\section{IgA-human recombinant (hr) tTG ELISA}

This analysis was performed in our laboratory with the Eu-tTG ${ }^{\circledR}$ IgA umana (Eurospital) kit according to the manufacturer's manual. As antigen, this method uses hr-tTG. The manufacturer is not willing to disclose any information about calcium addition. The cutoff level was defined according to the manufacturer's manual as $>7$ units (U).

\section{Endomysial autoantibody immunofluorescence (EMA)}

All EMA had been analyzed at the Clinical Microbiology and Immunology, Lund University Hospital, Lund, Sweden, by indirect immunofluorescence [5]. Patient serum was diluted 1:10 in PBS/Tween (Euroimmun, Lubeck, Germany) and applied to reaction fields of reagent tray containing tissue slides of primate intestine, liver and esophagus (Euroimmun, Lubeck, Germany). EMA were detected with fluorescein isothiocyanate conjugated goat anti-human IgA antibodies. Results were expressed as the highest dilution factor giving a positive fluorescence pattern in microscope. All sera manifesting fluorescence titer 1:10 or higher were considered to be positive.

\section{Intestinal biopsy}

A standard small bowel biopsy was taken with a Watson capsule from the jejunum intestinal mucosa. Standard sections were stained with haematoxylin and eosin and investigated in light microscope. A closer investigation for intraepithelial lymphocytes (IEL) was performed with CD3 immunohistochemistry. The upper limit of normal range of IEL count was set at $<25 / 100$ enterocytes [30]. Histopathological features were classified according to the criteria of Marsh [23] with some slight modifications and defined as: normal villous and crypt architecture and an IEL count $<25 / 100$ enterocytes (grade 0); normal villous and crypt architecture, but increased number of IEL (grade 1); partial villous atrophy (villous length exceeding width), crypt hyperplasia and increased 
number of IEL (grade 2); subtotal villous atrophy (villous width exceeding length), crypt hyperplasia and increased number of IEL (grade 3); and total villous atrophy, crypt hyperplasia and increased number of IEL (grade 4).

\section{Statistical methods}

Statistical differences between antibody frequencies were evaluated with the Chisquared test or the Fisher's exact test when appropriate. Antibody levels were expressed as median (range) and differences between the assays were tested with the Wilcoxon Signed Rank tested for significance. To measure change in antibody levels between CD children and disease controls, the Mann Whitney U-test was used for comparison. Linear regression examined whether increase in tTG antibody levels were related to severity of mucosa damage. tTG antibody levels were expressed as mean \pm SE. P-values $<0.05$ were considered significant. 


\section{Results}

Transglutaminase activity staining

Similarly to a lysate of human red blood cells the TNT-SP6 kit containing a lysate of rabbit reticulocytes displayed tTG activity (Fig. 1). The position of the fluorescent spot of the lysate on the agarose gel electrophotogram corresponded to that of the reference gp-tTG. Human blood plasma, on the other hand, displayed tTG activity at a position corresponding to Factor XIII. All transglutaminase activities observed were strictly calcium dependent.

\section{IgA and IgG anti-transglutaminase antibodies}

Whether calcium was present in the assay (Ca-RBA, Ca-ELISA) or not (EDTA-RBA, EDTA-ELISA), the overall detection of IgA-tTG among CD children did not differ between RBA and ELISA or if the commersial Eu-tTG ${ }^{\circledR}$ IgA umana ELISA test was used (Table 1). For the detection of IgG-tTG no significant difference was observed between Ca-RBA (48/51) and EDTA-RBA (49/51), while there was an increased number of IgGtTG positive CD children detected with Ca-ELISA (39/51) compared to EDTA-ELISA (26/51) $(p=0.0074)$. Still, more CD children were IgG-tTG positive with either Ca-RBA (48/51) or EDTA-RBA (49/51) compared to the Ca-ELISA (39/51), $(\mathrm{p}=0.004)$.

There was no change in binding levels of IgA-tTG in either CD children or the disease controls measured with Ca-RBA compared to EDTA-RBA, whereas IgG-tTG binding levels decreased a median 4.4 RU with Ca-RBA ( $p=0.002)$ in CD children (Fig. 2A). In contrast, binding levels of IgA-tTG and IgG-tTG increased a median log 0.24 AU and $\log$ 0.19 AU among CD children detected with Ca-ELISA compared to EDTA-ELISA, respectively ( $<<0.0001)$, while antibody binding levels remained unchanged among the disease controls (Fig. 2B). 
There was a high positive correlation between IgA-tTG levels detected with Ca-ELISA and Ca-RBA ( $\mathrm{r}=0.90, \mathrm{p}<0.0001)$. A positive correlation for IgA-tTG levels was also found between Ca-ELISA and the Eu-tTG ${ }^{\circledR}$ IgA umana ELISA $(r=0.92, \mathrm{p}<0.0001)$ as well as between Ca-RBA and the Eu-tTG ${ }^{\circledR}$ IgA umana ELISA ( $\left.r=0.84, \mathrm{p}<0.0001\right)$. When comparing binding levels of IgG-tTG a low correlation was observed between EDTA-ELISA and EDTA-RBA ( $\mathrm{r}=0.56, \mathrm{p}<0.0001)$, which increased between CaELISA and Ca-RBA ( $\mathrm{r}=0.67, \mathrm{p}<0.0001)$ and when Ca-ELISA was compared with EDTA-RBA (r=0.72, $\mathrm{p}<0.0001)$.

For every grade of intestinal mucosal damage detected binding levels of IgA-tTG increased a mean $9.0 \pm 4.2 \mathrm{RU}$ with Ca-RBA $(\mathrm{p}=0.039)$ and mean $9.6 \pm 4.4 \mathrm{RU}$ $(p=0.034)$ with EDTA-RBA (Fig. 3A). Similarly, binding levels of IgA-tTG increased a mean $\log 0.31 \pm 0.09$ AU with Ca-ELISA ( $\mathrm{p}=0.0013)$ and a mean $\log 0.26 \pm 0.08$ with EDTA-ELISA ( $\mathrm{p}=0.0018$ ) (Fig. 3B). In contrast, binding levels of IgG-tTG showed no significant linear increase for either of the RBA and ELISA methods. 


\section{Discussion}

This present study showed increased binding levels of IgA and IgG against native gptTG in ELISA containing calcium regardless of the severity of intestinal mucosal damage in children with CD. In contrast, the binding remained unchanged for IgA and, moreover, decreased for IgG against hr-tTG in the RBA with calcium.

In an earlier report [3], we observed significantly increased binding of IgA-tTG in sera from adult CD patients when calcium ions were added to gp-tTG ELISA. Indeed, our present results strengthen this view for ELISA also in children with CD. Similar results have been reported from other laboratories [9, 20, 21]. However, another group did not observe this calcium effect [22]. One explanation for the different results seen in various immunoassays could be the effect on the tTG conformation after calcium activation.

We have postulated that the thiol ester formed between the active site cysteine of tTG and a glutamine residue in a previously modified gliadin peptide constitutes the immunogen complex [3]. Thus, the enzyme is active during the process of becoming immunogen. Consequently, in order to optimize specificity and sensitivity, our strategy has been to keep the antigen in a native form using as physiological conditions as possible. Independent of source, tTG is a very fragile enzyme. Due to contaminating proteases, the gp-tTG from Sigma is rapidly degraded in solution. This is also true if the solution is frozen at $-20{ }^{\circ} \mathrm{C}$ [3]. Unfortunately, in most reports no details are given on the conditions of the handling of the enzyme. Similarly, due to commercial reasons, information is not given about possible calcium content in most of the kits available [12]. In the studies reporting no calcium effect, the enzyme has been biotinylated or coated at an extreme $\mathrm{pH}$ in a buffer system, hardly compatible with the presence of calcium ions. Obviously, in order to observe a calcium effect, the enzyme has to be handled in such a way that the enzyme activity is conserved. 
In our RBA, we did not observe an increased antibody binding in the presence of calcium. There was rather a tendency of reduced binding actually similarly to another report [22]. In these assays, human radio labeled tTG is expressed in a lysate of rabbit reticulocytes, a common technique for the preparation of human proteins intended for radioimmunoassays. In these cases, the missing or negative effect of calcium cannot be explained by poor laboratory practice. Instead, the presence of endogenous tTG activity from the reticulocytes, as shown in this work (Fig. 1), offers a possible explanation. In the presence of calcium the native rabbit tTG may compete with the translated human tTG to reduce the binding to the radio labeled enzyme.

Thus, the poor effects of calcium in the RBA, paradoxically, support the view that calcium causes a conformation of tTG, which leads to an enhanced binding of the antibody. Furthermore, reticulocytes contain a protein (band 4.2), which has homologies with other transglutaminases. The possible effect of protein 4.2 in the assays remains to be clarified. Obviously, when using animal cell systems for translating human cDNA, the potential complications caused by the presence of native proteins in the cell system has to be carefully considered.

The highest diagnostic sensitivity was found for IgA-tTG either using the RBA or the ELISA tests. While the performance of RBA was independent of calcium to bind IgAtTG, the reduction in binding with EDTA to IgA detected in the ELISA test underlines the importance of calcium to maintain the conformational integrity of tTG to be recognized as an autoantigen. The ELISA displayed a certain preference for binding IgA to gp-tTG, while the RBA did not seem to distinguish between the binding of IgA and IgG to hr-tTG. We speculate that the IgA antibodies may recognize a different tTG epitope in the ELISA than IgG since the IgG-tTG was more affected by absence of calcium and several of the sera were unable to bind autoantibodies. Another explanation on this difference could be that tTG in RBA is kept in solution during the formation of 
antigen-antibody complex, making all presumptive epitopes of tTG available and thus favour the binding situation of IgG.

In summary, calcium activation of native gp-tTG is needed for optimal binding of antibodies in ELISA. The reverse effects of calcium observed in RBA might be explained by competitive binding between native rabbit reticulocyte and hr ${ }^{35} \mathrm{~S}$-tTG. Autoantibody assays for tTG may need to take calcium into account for accurate diagnostic sensitivity and specificity for CD.

Acknowledgements: The authors would like to acknowledge Ester Lörinc, MD at the Department of Pathology, University Hospital MAS in Malmö, for reviewing all the biopsy sections in this study and for her superior teaching of the human intestinal histopathology. The study was funded by the Faculty of Medicine, Lund University, the Skåne Council Foundation for Research and Development, University Hospital MAS in Malmö, the Majblomman Fund and Anna and Edwin Berger's Foundation. 


\section{List of abbreviations}

CD, celiac disease; EMA, endomysial autoantibodies; hr, human recombinant; IEL, intraepithelial lymphocytes; gp, guinea pig; PAS, Protein A Sepharose; RBA, radioligand binding assay; tTG, tissue transglutaminase. 


\section{References}

[1] Aeschlimann D and Thomazy V. Protein crosslinking in assembly and remodelling of extracellular matrices: the role of transglutaminases. Connect Tissue Res 2000; 41: 127.

[2] Griffin M, Casadio R and Bergamini CM. Transglutaminases: nature's biological glues. Biochem J 2002; 368: 377-396.

[3] Roth E, Sjöberg K and Stenberg P. Biochemical and immuno-pathological aspects of tissue transglutaminase in coeliac disease. Autoimmunity 2003; 36: 221-226.

[4] Sjöström H, Lundin K, Molberg O, et al. Identification of a Gliadin T-cell Epitope in Coeliac Disease: General Importance of Gliadin Deamidation for Intestinal T-Cell Recognition. Scand J Immunol 1998; 48: 111-115.

[5] Chorzelski TP, Sulej J, Tchorzewska H, Jablonska S, Beutner EH and Kumar V. IgA class endomysium antibodies in dermatitis herpetiformis and coeliac disease. Ann N Y Acad Sci 1983; 420: 325-334.

[6] Dieterich W, Ehnis T, Bauer M, et al. Identification of tissue transglutaminase as the autoantigen of celiac disease. Nat Med 1997; 3: 797-801.

[7] Hansson T, Dahlbom I, Rogberg S, et al. Recombinant human tissue transglutaminase for diagnosis and follow-up of childhood coeliac disease. Pediatr Res 2002; 51: 700-705.

[8] Sblattero D, Berti I, Trevisiol C, et al. Human recombinant tissue transglutaminase ELISA: an innovative diagnostic assay for celiac disease. Am J Gastroenterol 2000; 95: 1253-1257.

[9] Sulkanen S, Halttunen T, Laurila K, et al. Tissue transglutaminase autoantibody enzyme-linked immunosorbent assay in detecting celiac disease. Gastroenterology 1998; 115: 1322-1328. 
[10] Leon F, Camarero C, R RP, et al. Anti-transglutaminase IgA ELISA: clinical potential and drawbacks in celiac disease diagnosis. Scand J Gastroenterol 2001; 36: 849-853.

[11] Vitoria JC, Arrieta A, Ortiz L and Ayesta A. Antibodies to human tissue transglutaminase for the diagnosis of celiac disease. J Pediatr Gastroenterol Nutr 2001; 33: 349-350.

[12] Wong RC, Wilson RJ, Steele RH, Radford-Smith G and Adelstein S. A comparison of 13 guinea pig and human anti-tissue transglutaminase antibody ELISA kits. J Clin Pathol 2002; 55: 488-494.

[13] Agardh D, Borulf S, Lernmark A and Ivarsson SA. Tissue transglutaminase immunoglobulin isotypes in children with untreated and treated celiac disease. J Pediatr Gastroenterol Nutr 2003; 36: 77-82.

[14] Bazzigaluppi E, Lampasona V, Barera G, et al. Comparison of tissue transglutaminase-specific antibody assays with established antibody measurements for coeliac disease. J Autoimmun 1999; 12: 51-56.

[15] Bonamico M, Tiberti C, Picarelli A, et al. Radioimmunoassay to detect antitransglutaminase autoantibodies is the most sensitive and specific screening method for celiac disease. Am J Gastroenterol 2001; 96: 1536-1540.

[16] Seissler J, Boms S, Wohlrab U, et al. Antibodies to human recombinant tissue transglutaminase measured by radioligand assay: evidence for high diagnostic sensitivity for celiac disease. Horm Metab Res 1999; 31: 375-379.

[17] Williams A, Annis P, Lock R, Unsworth D, Gale E and Bingley P. Evaluation of a high-throughput second antibody radiobinding assay of measuring IgA antibodies to human tissue transglutaminase. J Immunol Meth 1999; 228: 81-85. 
[18] Burgin-Wolff A, Gaze H, Hadziselimovic F, et al. Antigliadin and antiendomysium antibody determination for coeliac disease. Arch Dis Child 1991; 66: 941-947.

[19] Casadio R, Polverini E, Mariani P, et al. The structural basis for the regulation of tissue transglutaminase by calcium ions. Eur J Biochem 1999; 262: 672-679.

[20] Sardy M, Odenthal U, Karpati S, Paulsson M and Smyth N. Recombinant human tissue transglutaminase ELISA for the diagnosis of gluten-sensitive enteropathy. Clin Chem 1999; 45: 2142-2149.

[21] Feighery L, Collins C, Feighery C, et al. Anti-transglutaminase antibodies and the serological diagnosis of coeliac disease. Br J Biomed Sci 2003; 60:14-18.

[22] Nakachi K, Swift G, Wilmot D, et al. Antibodies to tissue transglutaminase: comparison of ELISA and immunoprecipitation assay in the presence and in the absence of calcium ions. Clin Chim Acta 2001; 304: 75-84.

[23] Marsh M. Gluten, major histocompability complex and small intestine. Gastroenterology 1992; 102: 330-354.

[24] Walker-Smith J, Guandalini S, Schmitz J, Shmerling D and Visakorpi J. Revised criteria for diagnosis of coeliac disease: Report of Working Group of European Society of Paediatric Gastroenterology and Nutrition (ESPGAN). Arch Dis Child 1990; 65: 909-911.

[25] Jeppson J, Laurell C and Franzen B. Agarose gel electrophoresis. Clin Chem 1979; 25: 629-638.

[26] Stenberg P and Stenflo J. A rapid and specific fluorescent activity staining procedure for transamidating enzymes. Anal Biochem 1979; 93: 445-452.

[27] Grubin C, Daniela T, Toivola B, et al. A novel radioligand binding assay to determine diagnostic accuracy of isoform-specific glutamic acid decarboxylase antibodies in childhood IDDM. Diabetologia 1994; 37: 344-450. 
[28] Falorni A, Ortqvist E, Persson B and Lernmark Å. Radioimmunoassys for glutamic acid decarboxylase (GAD65) and GAD65 autoantibodies using 35S or 3H recombinant human ligands. J Immunol Methods 1995; 86: 89-99.

[29] Agardh D, Nilsson A, Tuomi T, et al. Prediction of silent celiac disease at diagnosis of childhood Type 1 diabetes by tissue transglutaminase autoantibodies and HLA. Pediatric Diabetes 2001; 2: 58-65.

[30] Veress B, Franzén L, Bodin L and Borch K. Duodenal Intraepithelial Lymphocyte-Count Revisited. Scand J Gastroentrol 2004; 39: 138-144. 
Table 1. tTG antibodies measured with immunoassays with (Ca-RBA, Ca-ELISA) and

without calcium (EDTA-RBA, EDTA-ELISA).

\begin{tabular}{|c|c|c|c|c|c|c|c|}
\hline \multirow[b]{2}{*}{ Immunoassay } & \multicolumn{3}{|c|}{ Celiac Disease $(n=51)$} & \multicolumn{4}{|c|}{ Controls $(n=35)$} \\
\hline & $\mathbf{n}$ & $\%$ & $95 \% \mathrm{CI}$ & $\mathbf{n}$ & $\%$ & $95 \% \mathrm{CI}$ & P-value \\
\hline \multicolumn{8}{|l|}{$\underline{\text { IgA-tTG }}$} \\
\hline Ca-RBA & 50 & $98 \%$ & $94-100 \%$ & 1 & $2 \%$ & $0-5 \%$ & $<0.0001$ \\
\hline EDTA-RBA & 50 & $98 \%$ & $94-100 \%$ & 3 & $9 \%$ & $0-18 \%$ & $<0.0001$ \\
\hline Ca-ELISA & 50 & $98 \%$ & $94-100 \%$ & 4 & $11 \%$ & $0-23 \%$ & $<0.0001$ \\
\hline EDTA-ELISA & 47 & $92 \%$ & $85-100 \%$ & 3 & $9 \%$ & $0-18 \%$ & $<0.0001$ \\
\hline \multicolumn{8}{|l|}{ IgG-tTG } \\
\hline Ca-RBA & 48 & $94 \%$ & $87-100 \%$ & 1 & $2 \%$ & $0-5 \%$ & $<0.0001$ \\
\hline EDTA-RBA & 49 & $96 \%$ & $91-100 \%$ & 3 & $9 \%$ & $0-18 \%$ & $<0.0001$ \\
\hline Ca-ELISA & 39 & $76 \%$ & $64-89 \%$ & 8 & $23 \%$ & $8-37 \%$ & $<0.0001$ \\
\hline EDTA-ELISA & 26 & $51 \%$ & $37-65 \%$ & 6 & $17 \%$ & $4-30 \%$ & 0.003 \\
\hline Eu-tTG ${ }^{\circledR}$ IgA umana* & 50 & $98 \%$ & $94-100 \%$ & 3 & $9 \%$ & $0-18 \%$ & $<0.0001$ \\
\hline IgA-EMA & 48 & $94 \%$ & $87-100 \%$ & 2 & $6 \%$ & $0-14 \%$ & $<0.0001$ \\
\hline
\end{tabular}

Abbreviations: gp, guinea pig; hr, human recombinant; tTG, tissue transglutaminase;

RBA, radioligand binding assay; EMA, endomysial autoantibodies. *commersial ELISA kit. 


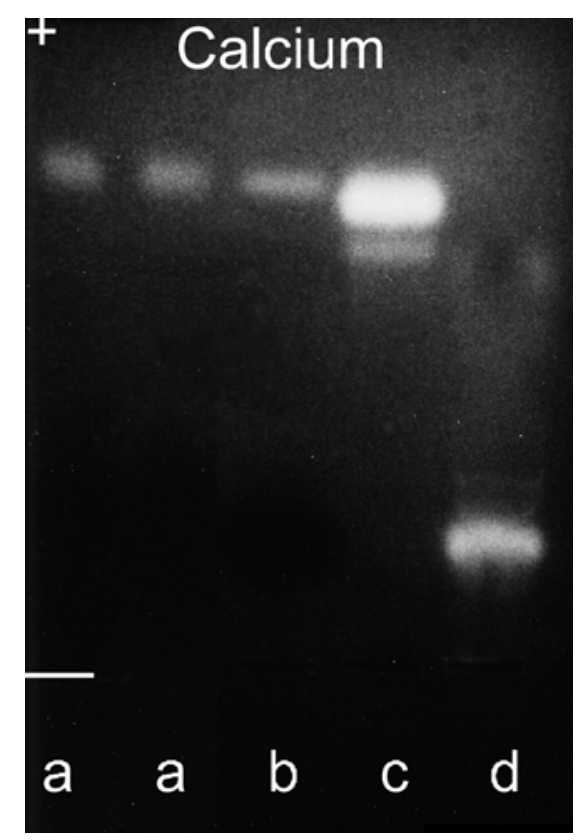



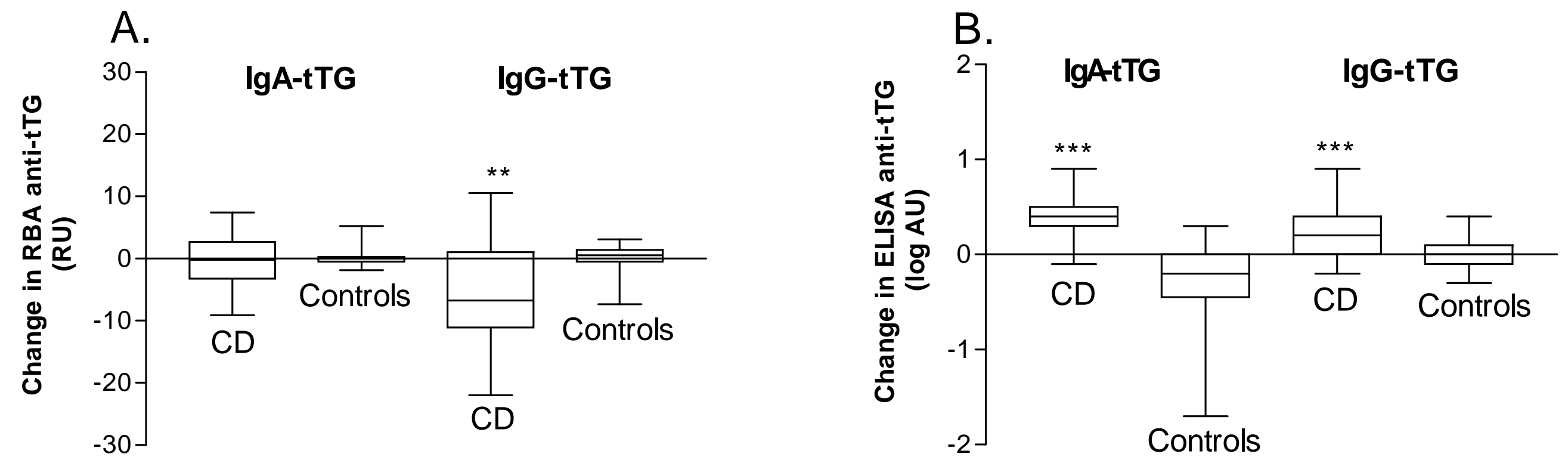
A.

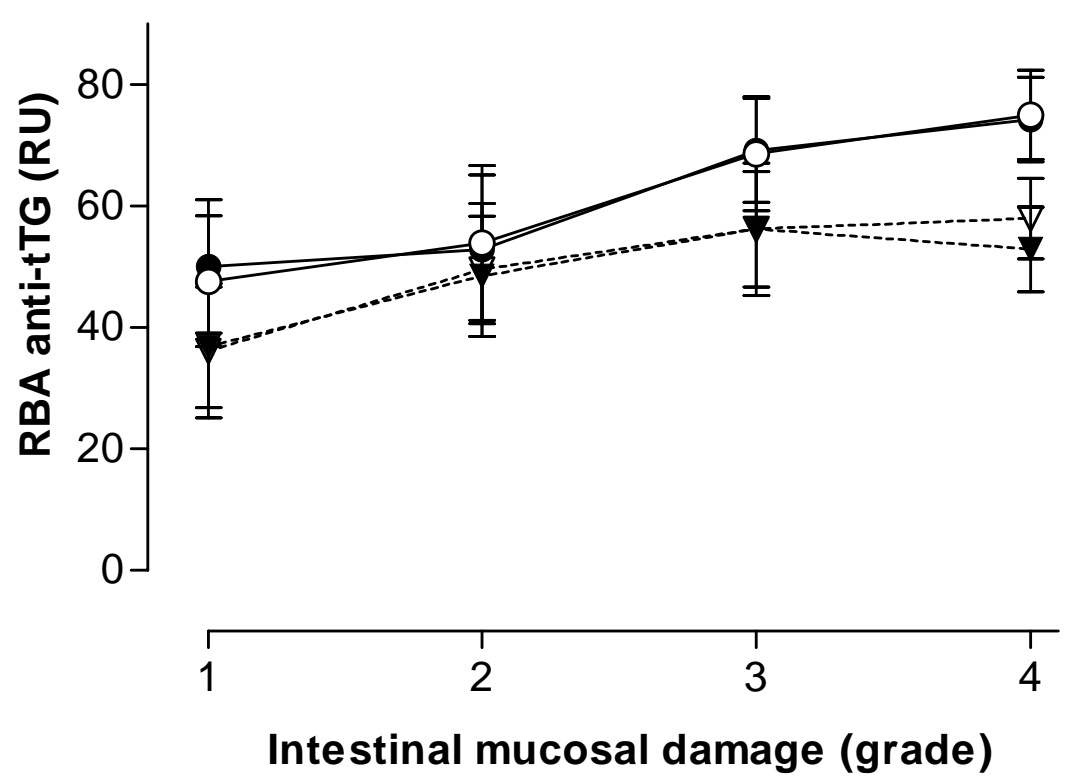

B.

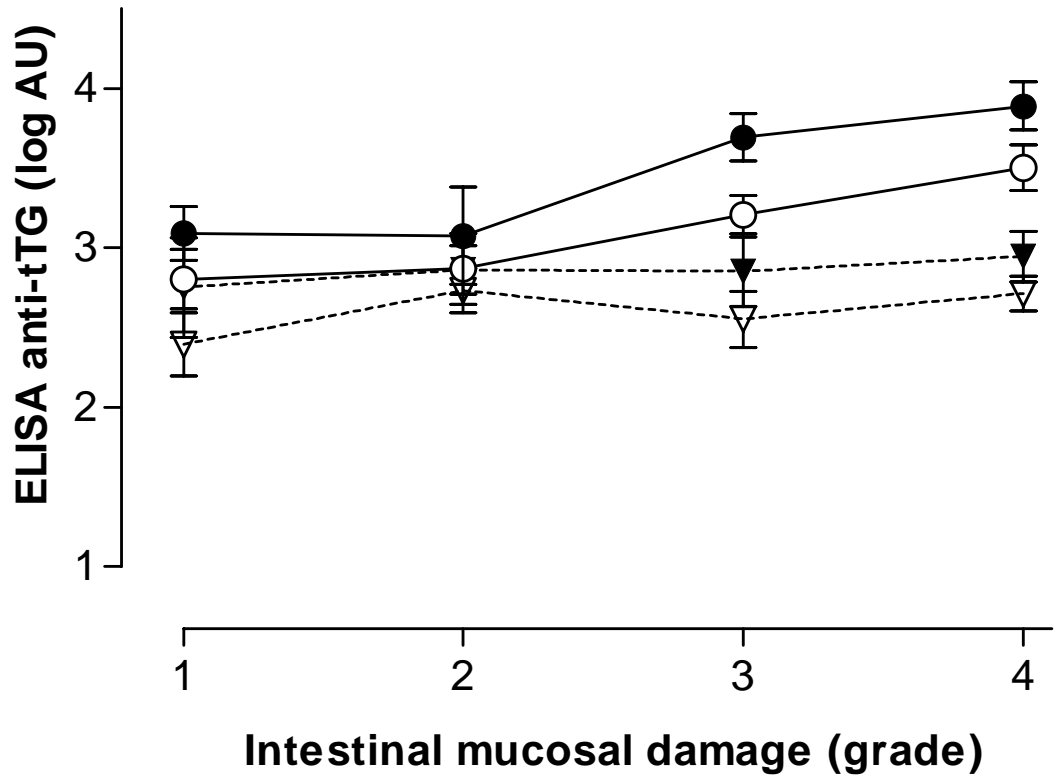

